Research Paper

\title{
Enhancement of Visuospatial Working Memory by Transcranial Direct Current Stimulation on Prefrontal and Parietal Cortices
}

Yousef Moghadas Tabrizi ${ }^{1}$ (D), Meysam Yavari Kateb ${ }^{2 *}$ (D), Shahnaz Shahrbanian ${ }^{3}$ (D)

1. Department of Sport Pathology and Corrective Exercises, Faculty of Sports and Health Sciences, University of Tehran, Tehran, Iran 2. Department of Behavioral and Cognitive Sports Sciences, Faculty of Sports and Health Sciences, University of Tehran, Tehran, Iran. 3. Department of Sports Science, Faculty of Humanities, Tarbiat Modares University, Tehran, Iran.

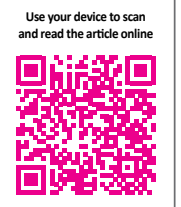

Citation Moghadas Tabrizi, Y., Yavari Kateb, M., \& Shahrbanian, S. (2023). Enhancement of Visuospatial Working Memory by Transcranial Direct Current Stimulation on Prefrontal and Parietal Cortices. Basic and Clinical Neuroscience, 14(1), 129-136. http://dx.doi.org/10.32598/bcn.2021.3275.1

oi http://dx.doi.org/10.32598/ben.2021.3275.1

Article info:

Received: 08 May 2021

First Revision: 14 Aug 2021

Accepted: 11 Sep 2021

Available Online: 01 Jan 2023

Keywords:

Spatial working memory,

Transcranial direct current stimulation (tDCS), computerized Corsi block tapping (CBT) task

\section{A B S T RA C T}

Introduction: Previous studies have reported dorsolateral prefrontal cortex (DLPFC) and posterior parietal cortex (PPC) activation during the performance of spatial working memory (SWM), therefore this study aims to compare the effect of transcranial direct current stimulation (tDCS) between these two areas.

Methods: Fifty-four healthy right-handed students ( 27 women, 27 men; age $=24.3 \pm 0.2$ years) were randomly assigned to an anodal group $(n=27)$ and a sham group $(n=27)$, each of these groups was divided into F4 (representing right DLPFC) or P4 (representing right PPC) subgroups, respectively. A computerized Corsi block tapping (CBT) task was used to measure SWM. The tDCS intervention consisted of five daily sessions with a direct current of $1.5 \mathrm{~mA}$ for 15 minutes on the F4 or P4 area of the brain at 24-hour intervals.

Results: Significant enhancement of the SWM span as well as a faster response was observed after anodal tDCS in both the anterior and posterior direction. Moreover, stimulation of the left DLPFC induced a faster reaction time compared to the right PPC.

Conclusion: Stimulation DLPFC and PPC, as an element of the frontoparietal network, showed SWM enhancement, with the DLPFC being more affected. Our finding provides new evidence to compare the effect of stimulation on the two main activated cortical areas during visual SWM.

\section{* Corresponding Author:}

Yavari Kateb, PhD.

Address: Department of Behavioral and Cognitive Sports Sciences, Faculty of Sports and Health Sciences, University of Tehran, Tehran, Iran.

Tel: +98 (21) 66405138

E-mail: meysam.Yavari@ut.ac.ir 


\section{Highlights}

- The study's results support the hypothesis that transcranial direct current stimulation (tDCS) can improve working memory.

- The results showed that both dorsolateral prefrontal cortex (DLPFC) and posterior parietal cortex (PPC) stimulation, as an element of the frontoparietal network, can enhancement spatial working memory.

- DLPFC stimulation induced a faster reaction time compared to the PPC.

\section{Plain Language Summary}

This study was conducted on university students. We introduced an auxiliary method to improve working memory ability. Working memory is like a temporary sticky note in the brain. It's a skill that lets us work with information without losing track of what we're doing. Various methods have been introduced to improve working memory, one of the new methods is the use of transcranial direct current stimulation (tDCS). tDCS is a method to stimulate the brain using constant and low direct current delivered via electrodes on the head. In the present study, we sought to investigate the effectiveness of tDCS in two points of the head related to working memory and compare its effectiveness. We found that tDCS may can be effective in both areas related to working memory, while one of the points being more effected.

\section{Introduction}

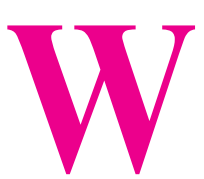

orking memory (WM) refers to the mental ability that allows a person to temporally store and manipulate a limited amount of information. WM functioning is necessary for complex cognitive tasks, such as reasoning, problem-solving, comprehension, and learning. Neuroimaging studies have demonstrated WM-related cortical activity in the sensory and prefrontal areas, the dorsolateral prefrontal cortex (DLPFC) plays a particularly crucial role (Curtis \& D'Esposito, 2003; Linden, 2007). In the classical model, WM includes phonological and visuospatial stores (two temporary buffers) as well as the central executive system (Baddeley \& Hitch, 1974). Spatial working memory (SWM), a specific type of WM, includes information within the spatial domain. Cortical high-relevant activity in the SWM network includes the DLPFC, posterior parietal cortex (PPC), and frontal eye field (Curtis \& D’Esposito, 2003; Vogel \& Machizawa, 2004). Among SWM-related cortical areas, the DLPFC seems to be mostly involved in selection operations (Bledowski et al., 2010).

The left DLPFC mostly controls verbal WM, while the visuospatial WM is mainly controlled by the right DLPFC (D'Esposito et al., 2000; Smith \& Jonides, 1999). Frontoparietal network activity has been identified as part of the WM function (Mottaghy et al., 2002) referring to the role of the parietal cortex in processing the spatial information of sensory cues and the role of the prefrontal cortex in maintaining this presentation. This neural processing in the dorsal stream includes spatial location. Frontoparietal network dysfunction leading to WM impairment has been seen in fibromyalgia (Seo et al., 2012), and schizophrenia patients (Kyriakopoulos et al., 2012).

Transcranial direct current stimulation (tDCS) is a non-invasive brain stimulation technique that modulates cortical activity by applying a weak electrical current. In this technique, cortical excitability is increased by an anodal (positive-charged) electrode and decreased by a cathodal (negative-charged) electrode. The duration of cortical excitation is prolonged and can persist for an extended long time, ranging from 5 to $90 \mathrm{~min}$ utes, depending on the length of stimulation (Nitsche \& Paulus, 2000). Several studies have recently confirmed that $\mathrm{tDCS}$ produces long-lasting neuroplastic changes, representing its potential therapeutic effects (Nitsche \& Paulus, 2001; Olma et al., 2013). tDCS effect on working memory, motor learning, and verbal frequency has also been investigated in previous studies (Fregni et al., 2005). Therefore, tDCS is considered a tool to enhance cognition ability in both normal persons and patients and has been used in the rehabilitation of cognitive function in neurologic disorders.

Most of the time, improvement in WM performance is reported for applying tDCS on the DLPFC of healthy subjects (Fregni et al., 2005) and patient groups (Nitsche et al., 2008). A meta-analytic review reported improvement in only speed but not the accuracy of WM perfor- 
mance using tDCS (Mancuso et al., 2016). In SWM, a specific subtype of WM, anodal tDCS over the right DLPFC has been recently found to enhance performance in "visuospatial function training" (Jeon \& Han, 2012). Furthermore, the effect of right DLPFC stimulation was shown by using a computerized Corsi block tapping (CBT) task, a widely used paradigm that measures visuospatial short-term and working memory (Wu et al., 2014). Giglia and the co-author showed the right DLPFC was more effective in enhancing SWM functioning compared to the left DLPFC (Giglia et al., 2014). Few studies were conducted to investigate the effect of right parietal tDCS on SWM performance (Heimrath et al., 2012). Their findings show that DLPFC and PPC are critical in SWM, but to our knowledge, no study has compared the effects of tDCS on these two main cortical areas in SMW performance. Hence, this randomized sham-controlled study was conducted to investigate the effects of tDCS on DLPFC and PPC to enhance SWM ability (span and response time) and then compare the effect of stimulation on these two areas.

\section{Materials and Methods}

Fifty-four healthy undergraduate students from similar educational backgrounds from Tehran University participated in the present study (27 women, 27 men, age: $24.30 \pm 0.20$ years). All of the participants were right-handed and had a normal or corrected-to-normal vision based on the Edinburgh handedness inventory (Oldfield, 1971). The participants were then randomly assigned into an anodal group $(\mathrm{A}=27)$ and a sham group $(\mathrm{S}=27)$, and each of these groups was divided into F4 (corresponding to the right DLPFC) or P4 (corresponding to the right PPC) sub-groups (A-F4=14, S-F4=13; A-P4=13, S-P4=14). Individuals with psychiatric or neurological disease and a history of alcohol or drug abuse were excluded. Before starting the study, written consent was obtained from all participants, and the study was approved by the Ethics Committee of Tehran University.

Computerized Corsi block tapping task (CBT): In a CBT task used to measure the SWM (De Renzi \& Nichelli, 1975), the visual targets are presented in different sequences, and the participants are requested to memorize the location and sequence of the presented targets. Then, they remember the location and sequence of the presentation both in forward and backward order (as a reversed sequenced). In the present study, a computerized form of the CBT task was used (Wu et al., 2014) in which 9 blue squares are presented as placeholders for the target demonstration in random locations on the screen. Then yellow targets were randomly shown for $500 \mathrm{~ms}$ in the blue squares. The participants were requested to memorize the location and sequences of the appearance of the yellow squares. Five $s$ after disappearing (retention interval), the participants were asked to point out the order and location of the appearance of the yellow squares using a computer mouse. The stimuli were presented on a 19-inch PC monitor screen from a distance of $57 \mathrm{~cm}$. The subjects were asked to respond as quickly and correctly as possible. Every individual SWM span was defined as the highest correct response at the level of presented yellow targets. The lowest/easiest level of the task started with only 2 appearances of the yellow targets and increased with each correct response by the participant. The task was terminated if the subject failed to correctly respond to two successive trials at the same level, and this level was defined as their SWM span.

Electrical stimulation was delivered by a tDCS device (Active Dose, manufactured by ActivaTeK) with sponge pads of $5 \times 7 \mathrm{~cm}^{2}$. The positive electrode was placed over the F4 or the $\mathrm{P} 4$ according to the international 10-20 EEG system, and the negative electrode in both conditions was placed over the left supraorbital in either the anodal or sham group. The intervention consisted of five daily sessions with a 24-h interval between them, and in each session, a direct current of $1.5 \mathrm{~mA}$ was applied for 15 minutes in the anodal group. For the sham group, the tDCS current was applied and then disconnected after 30 $\mathrm{s}$ without informing the participant. The pre-test measurement (CBT task) was performed before the first session and the post-test measurement after the fifth session.

\section{Results}

Descriptive characteristics of the participants: A total of 54 participants completed the study. Results of the performance of the Anodal and Sham groups did not significantly differ in terms of their reaction time (forward: $\mathrm{P}=0.895$, backward: $\mathrm{P}=0.768$ ) and span of response (forward: $\mathrm{P}=1$, backward: $\mathrm{P}=0.859$ ) at baseline.

\section{Memory span (Figure 1):}

Forward memory span: Table 1 presents the Mean \pm SD of the CBT span scores.

A mixed between-group analysis of variance (ANOVA) on the memory span of the CBT task (design: Group post-anodal/post sham+site F4/P4+group*site) detected a significant main effect for the group $\left(F=20.216, d_{f}=1\right.$, $\mathrm{P}=0.001, \eta \mathrm{p}^{2}=0.288$ ), but no significant effects for the site $\left(\mathrm{F}=0.985, \mathrm{~d}^{\mathrm{f}}=1, \mathrm{P}=0.326, \eta \mathrm{p}^{2}=0.019\right)$ or interac- 
Table 1. Mean $\pm S D$ and results from paired t-tests of the CBT task span forward and backward scores

\begin{tabular}{|c|c|c|c|c|c|c|c|}
\hline \multirow{2}{*}{$\begin{array}{l}\text { CBT Task } \\
\text { Direction }\end{array}$} & \multirow{2}{*}{$\begin{array}{c}\text { Site of } \\
\text { Stimulation }\end{array}$} & \multicolumn{2}{|c|}{ Mean \pm SD } & \multirow{2}{*}{ Difference $\mathrm{P}$} & \multicolumn{2}{|c|}{ Mean $\pm S D$} & \multirow{2}{*}{ Difference $\mathrm{P}$} \\
\hline & & $\begin{array}{l}\text { Pre-Anodal } \\
\text { tDCS }\end{array}$ & $\begin{array}{l}\text { Post-Anodal } \\
\text { tDCS }\end{array}$ & & $\begin{array}{l}\text { Pre-Sham } \\
\text { tDCS }\end{array}$ & $\begin{array}{l}\text { Post-Sham } \\
\text { tDCS }\end{array}$ & \\
\hline \multirow{3}{*}{ Forward } & F4 & $5.93 \pm 0.61$ & $6.50 \pm 0.94$ & 0.040 & $5.46 \pm 0.77$ & $5.54 \pm 0.77$ & 0.721 \\
\hline & P4 & $5 \pm 0.57$ & $6.77 \pm 0.72$ & 0.001 & $5.50 \pm 0.76$ & $5.71 \pm 0.82$ & 0.272 \\
\hline & Total & $5.48 \pm 0.75$ & $6.63 \pm 0.83$ & 0.001 & $5.48 \pm 0.75$ & $5.63 \pm 0.79$ & 0.294 \\
\hline \multirow{3}{*}{ Backward } & F4 & $5.14 \pm 0.66$ & $5.43 \pm 0.64$ & 0.040 & $5.08 \pm 0.95$ & $5 \pm 0.70$ & 0.829 \\
\hline & P4 & $5.08 \pm 0.76$ & $5.69 \pm 0.75$ & 0.005 & $5.21 \pm 0.69$ & $5.07 \pm 0.61$ & 0.435 \\
\hline & Total & $5.11 \pm 0.69$ & $5.56 \pm 0.69$ & 0.001 & $5.15 \pm 0.81$ & $5.04 \pm 0.64$ & 0.558 \\
\hline
\end{tabular}

tDCS: Transcranial direct current stimulation; CBT: Corsi block tapping.

NEUR SCIENCE

tion between group and site $\left(\mathrm{F}=0.043, \mathrm{~d}_{\mathrm{f}}=1, \mathrm{P}=0.836\right.$, $\left.\eta \mathrm{p}^{2}=0.001\right)$ was observed.

Backward memory span: A mixed design betweengroup ANOVA on the memory span of the CBT task by two-way ANOVA (design: Group post-anodal/post sham+site F4/P4+group*site) detected a significant main effect for the group $\left(\mathrm{F}=8.025, \mathrm{~d}_{\mathrm{f}}=1, \mathrm{P}=0.007, \eta \mathrm{p}^{2}=0.138\right)$, but no significant effect for the site $\left(\mathrm{F}=0.819, \mathrm{~d}_{\mathrm{f}}=1\right.$, $\left.\mathrm{P}=0.370, \eta p^{2}=0.016\right)$ or interaction between group and site $\left(\mathrm{F}=0.269, \mathrm{~d}_{\mathrm{f}}=1, \mathrm{P}=0.606, \eta \mathrm{p}^{2}=0.005\right)$ was observed.

A paired $\mathrm{t}$-test revealed that both forward $(\mathrm{t}=-5.428$, $\left.\mathrm{d}_{\mathrm{f}}=26, \mathrm{P}=0.001\right)$ and backward $\left(\mathrm{t}=-4, \mathrm{~d}_{\mathrm{f}}=26, \mathrm{P}=0.001\right)$ memory span improved significantly in the anodal group, but no significant difference was observed between the performance of pre- and post-tDCS in the sham group (forward: $\mathrm{t}=-1.072, \mathrm{~d}_{\mathrm{f}}=26, \mathrm{P}=0.294$; backward: $\mathrm{t}=0.593$, $\left.\mathrm{d}_{\mathrm{f}}=26, \mathrm{P}=0.558\right)$.
Reaction time (RT) (Figure 2):

Forward reaction time (RT): Table 2 presents the Mean \pm SD of the CBT reaction times.

A mixed between-group ANOVA on the reaction time of the CBT task (design: Group post anodal/post sham+site F4/P4+group $\times$ site) detected a significant main effect for the group $\left(\mathrm{F}=43.963, \mathrm{~d}_{\mathrm{f}}=1, \mathrm{P}=0.001, \eta \mathrm{p}^{2}=0.468\right)$, site $\left(\mathrm{F}=0.36 .406, \mathrm{~d}_{\mathrm{f}}=1, \mathrm{P}=0.001, \eta \mathrm{p}^{2}=0.421\right)$, and interaction between group and site $\left(\mathrm{F}=14.023, \mathrm{~d}_{\mathrm{f}}=1, \mathrm{P}=0.001\right.$, $\left.\eta p^{2}=0.219\right)$.

3-3-2: Backward reaction time: A mixed between-group ANOVA on the reaction time of the CBT task by twoway ANOVA (design: Group post anodal/post sham+site F4/P4+ group $\times$ site) detected a significant main effect for the group $\left(\mathrm{F}=7.563, \mathrm{~d}_{\mathrm{f}}=1, \mathrm{P}=0.008, \eta \mathrm{p}^{2}=0.131\right)$, but no significant effect for the site $\left(\mathrm{F}=0.115, \mathrm{~d}_{\mathrm{f}}=1, \mathrm{P}=0.736\right.$,

Table 2. Mean \pm SD and results from paired t-tests of the CBT task forward and backward reaction times

\begin{tabular}{|c|c|c|c|c|c|c|c|}
\hline \multirow{2}{*}{$\begin{array}{l}\text { CBT task } \\
\text { Direction }\end{array}$} & \multirow{2}{*}{$\begin{array}{c}\text { Site of } \\
\text { Stimulation }\end{array}$} & \multicolumn{2}{|c|}{ Mean士SD } & \multirow{2}{*}{$\begin{array}{c}\text { Difference } \\
\text { P }\end{array}$} & \multicolumn{2}{|c|}{ Mean $\pm S D$} & \multirow{2}{*}{$\begin{array}{c}\text { Difference } \\
\text { P }\end{array}$} \\
\hline & & $\begin{array}{l}\text { Pre-Anodal } \\
\text { TDCS }\end{array}$ & $\begin{array}{l}\text { Post-Anodal } \\
\text { TDCS }\end{array}$ & & $\begin{array}{l}\text { Pre-Sham } \\
\text { TDCS }\end{array}$ & $\begin{array}{l}\text { Post-Sham } \\
\text { TDCS }\end{array}$ & \\
\hline \multirow{3}{*}{ Forward } & F4 & $2471.28 \pm 231.84$ & $2034.72 \pm 131.89$ & 0.001 & $2505.81 \pm 155.33$ & $2450.92 \pm 110.21$ & .829 \\
\hline & P4 & $2599.98 \pm 201.79$ & $2426.98 \pm 188.99$ & 0.001 & $2571.76 \pm 126.77$ & $2542.74 \pm 147.85$ & .511 \\
\hline & Total & $2533.25 \pm 223.52$ & $2223.59 \pm 255.09$ & 0.001 & $2540.01 \pm 142.48$ & $2498.53 \pm 136.83$ & .187 \\
\hline \multirow{3}{*}{ Backward } & $\mathrm{F} 4$ & $2704.55 \pm 159.20$ & $2470.51 \pm 175.51$ & 0.003 & $2684.66 \pm 175.85$ & $2631.82 \pm 167.59$ & .442 \\
\hline & P4 & $2660.48 \pm 167.61$ & $2528.74 \pm 146.41$ & 0.001 & $2657.81 \pm 126.90$ & $2602.55 \pm 134.50$ & .378 \\
\hline & Total & $2683.33 \pm 161.69$ & $2498.55 \pm 161.99$ & 0.001 & $2670.74 \pm 150.04$ & $2616.64 \pm 149.10$ & .230 \\
\hline
\end{tabular}

tDCS: Transcranial direct current stimulation; CBT: Corsi block tapping.

NEUR SCIENCE 


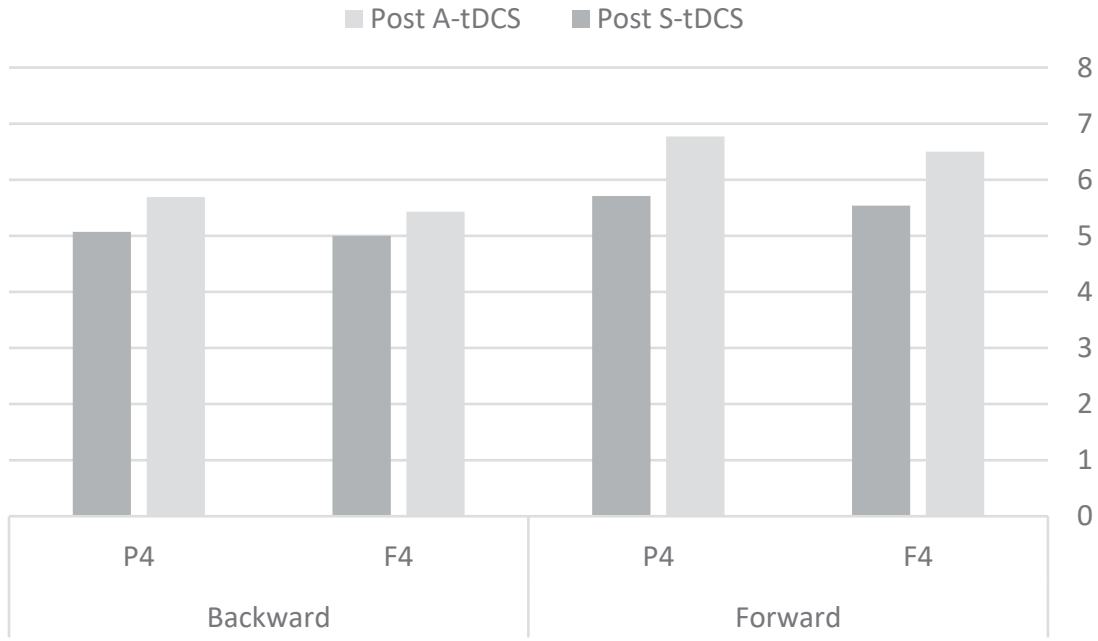

Figure 1. Forward and backward memory span in post anodal and sham groups in tow site F4 and P4

$\left.\eta \mathrm{p}^{2}=0.002\right)$ or interaction between group and site $\left(\mathrm{F}=1.047, \mathrm{~d}_{\mathrm{f}}=1, \mathrm{P}=0.311, \eta \mathrm{p}^{2}=0.021\right)$ was observed.

A paired t-test revealed that both forward $(\mathrm{t}=7.755$, $\left.\mathrm{d}_{\mathrm{f}}=26, \quad \mathrm{P}=0.001\right)$ and backward $\left(\mathrm{t}=5.034, \quad \mathrm{~d}_{\mathrm{f}}=26\right.$, $\mathrm{P}=0.001$ ) reaction time improved significantly in the anodal group. However, no significant difference was observed between the performances pre- and post tDCS in the sham group (forward: $\mathrm{t}=1.356, \mathrm{~d}_{\mathrm{f}}=26, \mathrm{P}=0.187$; backward: $\mathrm{t}=1.230, \mathrm{~d}_{\mathrm{f}}=26, \mathrm{P}=0.230$ ).

ANCOVAs, conducted separately on post anodal reaction time (RT) and post anodal WM span with controlled pre-anodal effects (pre anodal RT and pre anodal WM span as covariates), showed a non-significant differ- ence between the men and women's performances (RT: $\mathrm{F}=0.006, \mathrm{P}=0.940$, Span: $\mathrm{F}=0.116, \mathrm{P}=0.706$ ).

\section{Discussion}

The present study was conducted to investigate SWM recall performance (indexed by a computerized CBT task) in 54 healthy subjects before and after five sessions of sham-controlled tDCS over the right DLPFC or right PPC. The participants tolerated the intervention well, and none found the tDCS stimulation unpleasant. Results demonstrated an enhancement of the SWM span in both forward and backward directions after five sessions of anodal tDCS. However, no significant difference was found in the sham tDCS groups. Moreover, the anodal

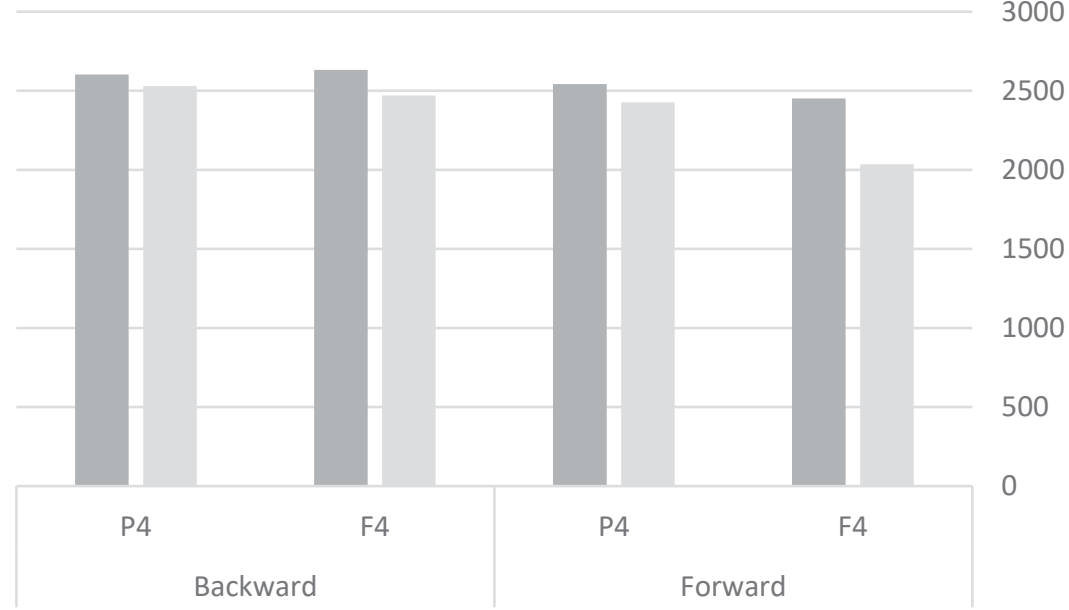

Figure 2. Forward and backward reaction time (RT) in post anodal and sham groups in tow site F4 and P4 
group responded faster than the sham group after five days of tDCS stimulation, and the right DLPFC stimulation induced a faster reaction time than the right PPC.

Neuroimaging investigations have previously reported SWM-related cortical hyperactivity, particularly in the prefrontal and PPC areas, during the maintenance phase (Ikkai \& Curtis, 2011). The frontoparietal network, which consists of the DLPFC and PP, plays an essential role in WM performance (Darki \& Klingberg, 2014). Functional magnetic resonance imaging (fMRI) findings have revealed that the PP cortex is also involved in SWM maintenance (Olesen et al., 2003; Vestergaard et al., 2011). In a cross-sectional study using functional magnetic resonance imaging (fMRI), WM capacity was correlated with BOLD activity in both frontal and parietal regions (Darki \& Klingberg, 2014).

TDCS is a non-invasive stimulant method that can modulate neural activity during cognitive function. An enhancement effect of increases in memory span and response after tDCS over the DLPFC has been reported (Wu et al., 2014).

Fregni et al. showed WM had a better performance when applying anodal tDCS over the left DLPFC compared to the opposite effect of applying rTMS on the same area (2005). They explained that the weak electrical current in tDCS causes a slight change in the resting potential of the stimulated neurons and lowers their depolarization threshold, while rTMS's potent stimulation effect induces action potential and disruption of information processing. Consistent with Brighina et al., this study demonstrated that the right DLPFC is involved in visuospatial WM performance (Adamova et al., 2018). Moreover, when comparing the right versus the left DLPFC, right-side anodal activation showed performance improvement in a visuospatial WM task (Adamova et al., 2018).

Our findings provide new evidence compared to the effects of stimulation on the two main activated cortical areas during visuospatial WM. TDCS stimulation of the DLPFC induced a faster response than the PPC in recall WM task performance. Some investigations have suggested that the DLPFC plays a role in the programming and executing appropriate motor responses during WM task performance (Hamidi et al., 2009; Pochon et al., 2001). DLPFC processing involves updating goal representations based on context information or task-related demands. Thus, DLPFC stimulation by tDCS could enhance its functioning and resulted in shortening recall response time. DLPFC, as an element of the frontoparietal network, is activated in the stimulus neural processing during the retention stage (Funahashi et al., 1993). However, the storage of perceptual attributes (Callicott et al., 1999) and maintenance of information, particularly spatial location, are processed in the parietal cortices (Olson \& Berryhill, 2009).

Our findings showed no difference in the memory span between the two sites (DLPFC and PP) after anodal stimulation. Other investigations also reported a tDCS effect on the memory span of both the DLPFC (Wu et al., 2014) and PP (Tseng et al., 2012). Both prefrontal and parietal hyperactivity after training of the working memory (including a visual-SWM task, a backward digit span task, and a letter span task) illustrated the involvement of these regions in the working memory span (Olesen et al., 2004). Additionally, a correlation of brain areas activity involved in the frontointraparietal network with WM spatial span tasks was reported (Klingberg, 2006). In the present study, the right DLPFC was chosen after considering the spatial processing in this region.

Furthermore, these results showed no significant difference between men and women's performance. Although it is accepted that men show an advantage in spatial processing and women excel at verbal tasks (Driscoll et al., 2005), Kaufman (2007) reported discrepancies according to test strategy and age of participants. Consistent with the present study, Shah et al. demonstrated no sex differences on the computerized-Corsi test, but male participants performed better than female participants on the standard Corsi test. They explained that the gender difference in performance on the standard Corsi test was due to the men's better spatial span, and no sex difference was observed in the computerized Corsi test, which require spatial organizational skills (Shah et al., 2013).

\section{Conclusion}

Some of the limitations in this study include a lack of stimulation in the paired area in the PP and DLPFC when comparing the left versus the right hemisphere. In addition, considering the low spatial resolution of tDCS, we cannot rule out the effect of stimulation on neighboring regions.

In conclusion, our study demonstrates that the improvement of visuospatial WM performance (both RT and span) was induced with tDCS over the prefrontal and post-parietal cortex, with a faster response in prefrontal stimulation. 


\section{Ethical Considerations}

\section{Compliance with ethical guidelines}

This study was approved by the Ethics Committee of the Tehran University of Medical Sciences (Code: IR.TUMS.VCR.REC.1397.436).

Funding

The paper was financial supported by the University of Tehran (Grant No. 25208/1/01).

\section{Authors' contributions}

All authors equally contributed to preparing this article.

\section{Conflict of interest}

The authors declared no conflict of interest.

\section{Acknowledgments}

The authors acknowledge the financial support of the University of Tehran.

\section{References}

Adamova, B., Kutilek, P., Cakrt, O., Svoboda, Z., Viteckova, S., \& Smrcka, P. (2018). Quantifying postural stability of patients with cerebellar disorder during quiet stance using three-axis accelerometer. Biomedical Signal Processing and Control, 40, 378-384. [DOI:10.1016/j.bspc.2017.09.025]

Baddeley, A. D., \& Hitch, G. (1974). Working memory. Psychology of Learning and Motivation, 8, 47-89. [DOI:10.1016/S00797421(08)60452-1]

Bledowski, C., Kaiser, J., \& Rahm, B. (2010). Basic operations in working memory: contributions from functional imaging studies. Behavioural Brain Research, 214(2), 172-179. [DOI:10.1016/j.bbr.2010.05.041] [PMID]

Callicott, J. H., Mattay, V. S., Bertolino, A., Finn, K., Coppola, R., \& Frank, J. A., et al. (1999). Physiological characteristics of capacity constraints in working memory as revealed by functional MRI. Cerebral Cortex, 9(1), 20-26. [DOI:10.1093/cercor/9.1.20] [PMID]

Curtis, C. E., \& D'Esposito, M. (2003). Persistent activity in the prefrontal cortex during working memory. Trends in Cognitive Sciences, 7(9), 415-423. [DOI:10.1016/S1364-6613(03)00197-9] [PMID]

D’Esposito, M., Postle, B. R., \& Rypma, B. (2000). Prefrontal cortical contributions to working memory: Evidence from eventrelated fMRI studies. In W. X., Schneider, A. M., Owen, \& J. Duncan (Eds), Executive Control and the frontal lobe: Current Issues (pp.3-11). Berlin: Springer. [DOI:10.1007/978-3-64259794-7_2]
Darki, F., \& Klingberg, T. (2014). The role of fronto-parietal and fronto-striatal networks in the development of working memory: A longitudinal study. Cerebral Cortex, 25(6), 1587-1595. [DOI:10.1093/cercor/bht352] [PMID]

De Renzi, E., \& Nichelli, P. (1975). Verbal and non-verbal short-term memory impairment following hemispheric damage. Cortex, 11(4), 341-354. [DOI:10.1016/S0010-9452(75)80026-8] [PMID]

Driscoll, I., Hamilton, D. A., Yeo, R. A., Brooks, W. M., \& Sutherland, R. J. (2005). Virtual navigation in humans: The impact of age, sex, and hormones on place learning. Hormones and Behavior, 47(3), 326-335. [DOI:10.1016/j.yhbeh.2004.11.013] [PMID]

Fregni, F., Boggio, P. S., Nitsche, M., Bermpohl, F., Antal, A., \& Feredoes, E., et al. (2005). Anodal transcranial direct curren stimulation of prefrontal cortex enhances working memory. Experimental Brain Research, 166(1), 23-30. [DOI:10.1007] s00221-005-2334-6] [PMID]

Funahashi, S., Bruce, C. J., \& Goldman-Rakic, P. S. (1993). Dorsolateral prefrontal lesions and oculomotor delayed-response performance: Evidence for mnemonic" scotomas". The Journal of Neuroscience, 13(4), 1479-1497. [DOI:10.1523/JNEUROSCI.13-04-01479.1993] [PMID] [PMCID]

Giglia, G., Brighina, F., Rizzo, S., Puma, A., Indovino, S., \& Maccora, S., et al. (2014). Anodal transcranial direct current stimulation of the right dorsolateral prefrontal cortex enhances memory-guided responses in a visuospatial working memory task. Functional Neurology, 29(3), 189. [Link]

Hamidi, M., Tononi, G., \& Postle, B. R. (2009). Evaluating the role of prefrontal and parietal cortices in memory-guided response with repetitive transcranial magnetic stimulation. Neuropsychologia, 47(2), 295-302. [DOI:10.1016/j.neuropsychologia.2008.08.026] [PMID] [PMCID]

Heimrath, K., Sandmann, P., Becke, A., Müller, N. G., \& Zaehle, T. (2012). Behavioral and electrophysiological effects of transcranial direct current stimulation of the parietal cortex in a visuo-spatial working memory task. Frontiers in Psychiatry, 3 56. [DOI:10.3389/fpsyt.2012.00056] [PMID] [PMCID]

Ikkai, A., \& Curtis, C. E. (2011). Common neural mechanisms supporting spatial working memory, attention and motor intention. Neuropsychologia, 49(6), 1428-1434. [DOI:10.1016/j. neuropsychologia.2010.12.020] [PMID] [PMCID]

Jeon, S. Y., \& Han, S. J. (2012). Improvement of the working memory and naming by transcranial direct current stimulation Annals of Rehabilitation Medicine, 36(5), 585-595. [DOI:10.5535/ arm.2012.36.5.585] [PMID] [PMCID]

Kaufman, S. B. (2007). Sex differences in mental rotation and spatial visualization ability: Can they be accounted for by differences in working memory capacity? Intelligence, 35(3), 211 223. [DOI:10.1016/j.intell.2006.07.009]

Klingberg, T. (2006). Development of a superior frontal-intraparietal network for visuo-spatial working memory. Neuropsychologia, 44(11), 2171-2177. [DOI:10.1016/j.neuropsychologia.2005.11.019] [PMID]

Kyriakopoulos, M., Dima, D., Roiser, J. P., Corrigall, R., Barker, G. J., \& Frangou, S. (2012). Abnormal functional activation and connectivity in the working memory network in early-onset schizophrenia. Journal of the American Academy of Child \& Adolescent Psychiatry, 51(9), 911-920. e912. [DOI:10.1016/j. jaac.2012.06.020] [PMID] 
Linden, D. E. (2007). The working memory networks of the human brain. The Neuroscientist, 13(3), 257-267. [DOI:10.1177/1073858406298480] [PMID]

Mancuso, L. E., Ilieva, I. P., Hamilton, R. H., \& Farah, M. J. (2016). Does transcranial direct current stimulation improve healthy working memory?: A meta-analytic review. Journal of Cognitive Neuroscience, 28(8), 1063-1089. [DOI:10.1162/ jocn_a_00956] [PMID]

Mottaghy, F. M., Döring, T., Müller-Gärtner, H. W., Töpper, R., \& Krause, B. J. (2002). Bilateral parieto-frontal network for verbal working memory: An interference approach using repetitive transcranial magnetic stimulation (rTMS). European Journal of Neuroscience, 16(8), 1627-1632. [DOI:10.1046/j.14609568.2002.02209.x] [PMID]

Nitsche, M. A., Cohen, L. G., Wassermann, E. M., Priori, A. Lang, N., \& Antal, A., et al. (2008). Transcranial direct current stimulation: State of the art 2008. Brain Stimulation, 1(3), 206223. [DOI:10.1016/j.brs.2008.06.004] [PMID]

Nitsche, M. A., \& Paulus, W. (2000). Excitability changes induced in the human motor cortex by weak transcranial direct current stimulation. The Journal of Physiology, 527(3), 633-639. [DOI:10.1111/j.1469-7793.2000.t01-1-00633.x] [PMID] [PMCID]

Nitsche, M. A., \& Paulus, W. (2001). Sustained excitability elevations induced by transcranial DC motor cortex stimulation in humans. Neurology, 57(10), 1899-1901. [DOI:10.1212/ WNL.57.10.1899] [PMID]

Oldfield, R. C. (1971). The assessment and analysis of handedness: The Edinburgh inventory. Neuropsychologia, 9(1), 97-113. [DOI:10.1016/0028-3932(71)90067-4] [PMID]

Olesen, P. J., Nagy, Z., Westerberg, H., \& Klingberg, T. (2003). Combined analysis of DTI and fMRI data reveals a joint maturation of white and grey matter in a fronto-parietal network. Cognitive Brain Research, 18(1), 48-57. [DOI:10.1016/j.cogbrainres.2003.09.003] [PMID]

Olesen, P. J., Westerberg, H., \& Klingberg, T. (2004). Increased prefrontal and parietal activity after training of working memory. Nature Neuroscience, 7(1), 75-79. [DOI:10.1038/ nn1165] [PMID]

Olma, M. C., Dargie, R. A., Behrens, J. R., Kraft, A., Irlbacher, K., \& Fahle, M., et al. (2013). Long-term effects of serial anodal tDCS on motion perception in subjects with occipital stroke measured in the unaffected visual hemifield. Frontiers in $\mathrm{Hu}$ man Neuroscience, 7, 314. [DOI:10.3389/fnhum.2013.00314] [PMID] [PMCID]

Olson, I. R., \& Berryhill, M. (2009). Some surprising findings on the involvement of the parietal lobe in human memory. Neurobiology of Learning and Memory, 91(2), 155-165. [DOI:10.1016/j. nlm.2008.09.006] [PMID] [PMCID]

Pochon, J. B., Levy, R., Poline, J. B., Crozier, S., Lehéricy, S., \& Pillon, B., et al. (2001). The role of dorsolateral prefrontal cortex in the preparation of forthcoming actions: An fMRI study. Cerebral Cortex, 11(3), 260-266. [DOI:10.1093/cercor/11.3.260] [PMID]

Seo, J., Kim, S. H., Kim, Y. T., Song, H. J., Lee, J. J., \& Kim, S. H., et al. (2012). Working memory impairment in fibromyalgia patients associated with altered frontoparietal memory network. PloS One, 7(6), e37808. [DOI:10.1371/journal.pone.0037808] [PMID] [PMCID]
Shah, D. S., Prados, J., Gamble, J., De Lillo, C., \& Gibson, C. L. (2013). Sex differences in spatial memory using serial and search tasks. Behavioural Brain Research, 257, 90-99. [DOI:10.1016/j.bbr.2013.09.027] [PMID]

Smith, E. E., \& Jonides, J. (1999). Storage and executive processes in the frontal lobes. Science, 283(5408), 1657-1661. [DOI:10.1126/science.283.5408.1657] [PMID]

Tseng, P., Hsu, T. Y., Chang, C. F., Tzeng, O. J., Hung, D. L., \& Muggleton, N. G., et al. (2012). Unleashing potential: Transcranial direct current stimulation over the right posterior parietal cortex improves change detection in low-performing individuals.The Journal of Neuroscience: The Official Journal of The Society for Neuroscience, 32(31), 10554-10561. [DOI:10.1523/ JNEUROSCI.0362-12.2012] [PMID] [PMCID]

Vestergaard, M., Madsen, K. S., Baaré, W. F., Skimminge, A., Ejersbo, L. R., \& Ramsøy, T. Z., et al. (2011). White matter microstructure in superior longitudinal fasciculus associated with spatial working memory performance in children. Journal of Cognitive Neuroscience, 23(9), 2135-2146. [DOI:10.1162/ jocn.2010.21592] [PMID]

Vogel, E. K., \& Machizawa, M. G. (2004). Neural activity predicts individual differences in visual working memory capacity. Nature, 428(6984), 748-751. [DOI:10.1038/nature02447] [PMID]

Wu, Y. J., Tseng, P., Chang, C. F., Pai, M. C., Hsu, K. S., \& Lin C. C., et al. (2014). Modulating the interference effect on spatial working memory by applying transcranial direct current stimulation over the right dorsolateral prefrontal cortex. Brain and Cognition, 91, 87-94. [DOI:10.1016/j.bandc.2014.09.002] [PMID] 